\title{
Learning and change
}

Change is inevitable and often desired, the result of concentrated work and effort. Sometimes attention becomes so focused on one aspect of a task, that even dramatic, undesired changes in other areas go unnoticed or dismissed as inevitable. As scientific knowledge and technology expands, are we working harder and harder to teach scientific facts and concentrating less on the humanistic aspects of medicine?

First year medical students believe that medicine is the best of all professions and worthy of the time and energy costs. By graduation, many appear cynical. ${ }^{1-3}$ These shifts in attitude may not be as widely appreciated as the well documented changes that occur in students' scientific knowledge.

Students begin medical school recognising that they will need to learn a large volume of material. Still they are often surprised by the amount of material presented and the time needed to learn even a fraction of it. Some become discouraged and question their own capabilities. As they progress in school, they recognise that even practising physicians do not know everything and are fallible.

When we asked fourth year medical students what were the most surprising and difficult aspects of medical school, the majority focused on the amount of study time needed to learn the required material. None commented that the information was complicated, just that the amount appeared overwhelming at times. Students used the following phrases when describing the effects of long study hours: "social isolation", "grind of study", "lack of sleep", "give up everything", and difficulty "maintaining good spirits when demands seem impossible".

Even when there was no fear of failing, students often found it difficult to maintain their self-perceptions as competent and intellectually capable. They viewed simply passing as compromising their own expectations. One student related that the most difficult aspect of medical school was "going from the top of the class to the middle".

As students focus on learning the voluminous amount of scientific information, they spend less time with family and friends. Many are concerned about how the long study hours will affect their personal relationships. ${ }^{4}$ Studying encroaches on and sometimes replaces extracurricular activities. One of our students wrote that the most difficult aspect of medical school was "learning and keeping a healthy balance between medicine and other life interests".

Most students learn to mask these thoughts and feelings. ${ }^{5}$ Some become detached and reluctant to express disappointments. ${ }^{6}$ Gradually, values shift. For example, interests in psychosocial and humanistic issues weaken. ${ }^{7}$

To survive the rigors of medical school, students adapt by learning what is necessary to pass and do well academically. Dominant emphasis on one aspect of life

1 Rothman AI. Learning environment of a medical school: expectations versus perceptions of a first-year class. $\mathcal{F}$ Med Educ 1970; 4: 289-92. Wolf TM, Balson PM, Faucett JM, Randall HM. A retrospective study of attitude change during medical education. Med Educ 1989; 23: 19-23. Schwartz AH, Swartzburg M, Lieb J, Slaby AE. Medical
process of disillusionment. Med Educ 1978; 12: 182-5.

4 Fields SA, Toffler WL. Hopes and concerns of a first-year medical school Fields SA, Toffler WL. Hopes and
class. Med Educ 1993; 27: $124-9$. invariably changes values in other areas. Medical school tests measure how well students acquire scientific knowledge. This educational environment, which focuses on the acquisition of knowledge, shifts values away from psychosocial issues.

Thus expansion of scientific information and technology becomes both a blessing and a curse. Time, like money, is limited. Time spent acquiring scientific facts shifts emphasis away from the doctor-patient relationship. To prevent this cycle from continuing we must develop ways to support and strengthen humanistic values which may be pushed aside in the rigorous acquisition of medical knowledge. This is where technology may assist and/or lead us astray. Learning to make effective use of computers could eliminate the need to learn so many facts, freeing up time to learn how to listen to patients' fears and concerns, and not just the concrete facts about the location and character of their physical pain. The time previously spent on acquisition of basic scientific knowledge which expands and changes at such a rate that even the brightest student's fund of knowledge becomes outdated in five years, might profitably shift to learning the hands-on physical diagnostic skills that once characterised the clinician.

However, if computer training is an add-on to an already overloaded curriculum, then it may increase rather than diminish the problem. We must start subtracting, not adding to the volume of material to be assimilated. We must learn how to let technology free physicians to be with patients, strengthening a relationship that may comfort and heal.

We conclude that medical school and postgraduate training involves both the accumulation of scientific information and important changes in values and attitudes. All of us learn best by example. Students are learning exactly what we teach, just as we teach what we learned. We must take seriously students' and resident physicians' concerns about balancing psychosocial needs with the time commitment required to learn the science of medicine. Otherwise, we may be left with more science and little art in the practice of medicine, with science and technology eclipsing humanistic values.

KAY F MCFARLAND
DONNA R RHOADES
Department of Medicine,
University of South Carolina,
Two Richland Medical Park, Suite 506,
Columbia, SC 29203, USA

Accepted 21 September 1995

5 Spiro H. What is empathy and can it be taught? Ann Intern Med 1992; 116:

6 Tiberius RG, Sackin HD, McLean A. Medical students' early expectations Tiberius RG, Sackin HD, McLean A. Medical students' early expectations
and later opinions of aspects of their first year. Acad Med 1989; 64: 538-42. 7 Dufort F, Maheux B. When female medical students are the majority: do numbers really make a difference? $f$ Am Med Women's Assoc 1995; 50: 4-6. 